\title{
A Hermenêutica como Metodologia do Design
}

\section{La hermenéutica como metodología de diseño}

DOI: $10.46814 /$ lajdv4n1-004

Recebimento dos originais: 01/12/2021

Aceitação para publicação: 19/01/2022

\section{Liliana Cristina Marques Soares e Aparo \\ Doutoramento em Design}

Instituto Politécnico de Viana do Castelo - IPVC, Portugal \& Centro de Investigação em Arquitetura, Urbanismo e Design (CIAUD) da Faculdade de Arquitetura da Universidade de Lisboa (FAULisboa)

Rua Escola Industrial e Comercial Nun'Álvares, 34. 4900-347 Viana do Castelo, Portugal

E-mail: lsoares@estg.ipvc.pt

\section{Ermanno Aparo}

Pós-Doutoramento em Design

Instituto Politécnico de Viana do Castelo - IPVC, Portugal \&

Centro de Investigação em Arquitetura, Urbanismo e Design (CIAUD) da Faculdade de

Arquitetura da Universidade de Lisboa (FA-ULisboa)

Rua Escola Industrial e Comercial Nun'Álvares, 34. 4900-347 Viana do

Castelo, Portugal

E-mail: aparo@estg.ipvc.pt

\section{RESUMO}

Este artigo pondera acerca da interpretação como método e da apropriação da hermenêutica como metodologia projetual capaz de explicar o processo do design. Neste estudo é proposta uma abordagem de fundamentação arqueológica (Foucault, 1966) acerca do fenómeno da linguagem como entidade portadora de significado. O design parte do relacionamento entre sujeito e contexto, do tempo, da mudança e da advertência como factores estratégicos para operar. $\mathrm{O}$ texto releva a hipótese do ciclo hermenêutico como alternativa às metodologias clássicas.

Palavras Chave: Hermenêutica fenomenológica, linguagem, processo do design.

\section{RESUMEN}

Este artículo reflexiona sobre la interpretación como método y la apropiación de la hermenéutica como metodología proyectual capaz de explicar el proceso de diseño. En este estudio se propone un enfoque de fundamentación arqueológica (Foucault, 1966) sobre el fenómeno del lenguaje como portador de significado. El diseño parte de la relación entre el sujeto y el contexto, del tiempo, el cambio y la advertencia como factores estratégicos para operar. El texto destaca la hipótesis del ciclo hermenéutico como alternativa a las metodologías clásicas.

Palabras clave: hermenéutica fenomenológica, lenguaje, proceso de diseño. 


\section{A INTERPRETAÇÃO COMO FENÓMENO EXPERIENCIAL}

Embora o sentido etimológico da palavra interpretação apresente diversos significados, nesta investigação interessa apresentar o sentido da interpretação como processo de design. A escolha de uma palavra que tenha a autonomia e a distanciação para assumir um duplo sentido: contribuir para a fundamentação da interpretação como método em design e assumir o papel de metodologia projectual em design. Para isso, o designer deve aprender, por meio da interpretação, a ser objectivo. Como escreveu Paul Ricouer, "a interpretação entendida filosoficamente, nada mais é do que uma tentativa de tornar produtivas a alienação e a distanciação.” (Ricoeur, 2005, p.65). O conceito de distanciação, oriundo da interpretação como condição para a compreensão, pode ser abordado como a condição para que o designer se afaste, se abstraia para saber escolher e garantir a objectividade em relação aquilo que pretende atingir.

Como intérprete, o designer toma consciência da apropriação ou da desapropriação e do conceito de produção, de criação, de obra, que lhe permitem alcançar um significado para a sua determinação e para a sua resposta projectual. “À maneira de um texto, cuja significação se liberta das condições iniciais da sua produção, a acção humana tem um peso que não se reduz à sua importância na situação inicial da sua aparição, mas permite a reinscrição do seu sentido em novos contextos" (Ricouer, 1989, p.177). Esta acção de dar significado à cultura material pode ser alcançada por meio da deslocação de signos culturais, cujo mediador é a linguagem.

Então, nesta altura parece importante a apropriação da noção de linguagem, uma vez que ela é mais do que simples mediadora entre o sujeito e a realidade. Ela não é só aparência. A linguagem é portadora de significado e, nesta investigação, o meio expressivo para definir a expressão metodológica referente à interpretação como proposta de método em design em alternativa às metodologias projectuais clássicas.

\section{O PAPEL DA LINGUAGEM NA DEFINIÇÃO DA METODOLOGIA}

A linguagem é, como explica Hans-Georg Gadamer, a propósito do ponto de vista da interpretação, “(...) a primeira interpretação global do mundo e por isso não se pode substituir com nada (...)" (Gadamer, 2002, p.82). Historicamente, a afirmação de Gadamer parece indicar que nem sempre a linguagem foi compreendida como uma entidade que tem um significado e que não serve apenas para designar ou classificar as coisas. Este caminho parece anunciar que interpretar é conhecer, por meio da aplicação de uma expressão próxima da palavra interpretação que não passa pela substituição de uma palavra por outra, como um sinónimo, mas pela associação de factores que colaborem para qualificar o momento da experiência da interpretação. 
No design, a proposta de Gadamer poderá significar que este processo depende do relacionamento com factores vastos, como o contexto, a cultura, as novas capacidades tecnológicas, o risco, o desconhecido, a criação. Em ser capaz de exprimir o que é possível e apropriado. Este modo de operar denuncia uma tendência para criar várias alternativas, ao contrário de fórmulas, que são analisadas, avaliadas e propostas como trajecto para alcançar a proposta final, "this modelling, testing and modifying is the central, iterative activity of the design process.” (Cross, 2006, p.34). Então, a análise ao fenómeno da linguagem pode contribuir para a compreensão do processo do design.

O conceito de ser (e de não ser) da linguagem como ponto de partida para realizar o exercício da interpretação, é reforçado por Michel Foucault (1966) numa análise à legitimidade da linguagem em relação às coisas. Foucault, actuando um processo histórico-etimológico que lhe permitirá dissecar os métodos de interpretação da linguagem utilizados ao longo dos séculos no contexto ocidental, identificará que a linguagem era apenas utilizada para representar algo. Foucault referia-se a momentos da história como o período do séc. XVI ou o período da Revolução Industrial, em que a linguagem servia apenas de mediadora da cultura material. Este processo de analisar os métodos de interpretação da linguagem, permitiu a Foucault verificar porque razão a proposta do processo do 'método da fundamentação arqueológica' era a chave para considerar a linguagem como entidade e a sua aplicação num determinado contexto. Este método de análise comparativa parece ser uma hipótese de processo metodológico a ponderar no design.

Ainda acerca da arte de saber interpretar, Roland Barthes (1957) adverte para o erro constante de se confundirem os métodos da crítica na avaliação da realidade. Barthes defende que quando se cria uma linguagem está-se a atribuir significado à realidade e não a representá-la. Se a linguagem apenas serve para representar, torna-se num significante e isso poderia significar que ela era apenas uma imagem da realidade. Barthes sugere que se aplique ou um método ideológico ou um método semiólogo. Estas duas hipóteses de Barthes podem orientar esta investigação para a escolha de uma expressão capaz de atribuir significado à palavra interpretação e não uma expressão que apenas a substituía.

No design, interessa a apropriação de uma palavra que mantenha a sua função signo, a aparência que lhe confere a possibilidade de ser transposta para um outro tempo, para outros contextos e que contempla a função significado da cultura material. Neste sentido, para conduzir esta investigação para hipóteses que fundamentem a interpretação como método em design, é necessário:

1) reconhecer a ideia de identidade, e de não identidade, numa entidade;

2) adoptar a lógica do exercício do 'método da fundamentação arqueológica' para reforçar um método em alternativa a outro(s);

3) encontrar uma palavra que atribua sentido a uma realidade; 
4) relacionar os factores caracterizadores do tempo e da cultura;

5) realizar a técnica da distanciação para se tornar objectivo;

6) compreender o processo fenomenológico para reconhecer a aparência e o significado na interpretação;

Hipóteses de palavras como a semiótica e a hermenêutica surgem como propostas de metodologias que se referem à interpretação. Palavras que na linguagem, atribuem sentido à cultura material, quando atribuir também significa parecer como foi explicado anteriormente. Embora à partida, as duas palavras pareçam ser da mesma natureza e por isso se depreenda que ambas contêm o mesmo sentido é necessário procurar as semelhanças e as diferenças que existem entre elas. Este processo de avaliação é importante, porque fundamentará a apropriação e a escolha da(de) palavra(s) como metodologia projectual do design.

\section{HIPÓTESES DE METODOLOGIAS PARA FUNDAMENTAR A INTERPRETAÇÃO COMO MÉTODO EM DESIGN}

Segundo alguns autores Krippendorff (2005), Bürdek (1994), a semiótica e a hermenêutica são as ciências que deram maior importância ao design no século XX.

A semiótica enquanto teoria dos signos ocupa-se também da comunicação sendo que uma das funções do design é a função comunicativa. Acerca da importância do código e da análise semiótica, já no século XVIII o filósofo David Hume defendia que "se o leitor (o público) possuir esse determinado código (pelo menos em parte) existirá para ele a facilidade suficiente para lhe permitir a descodificação do próprio texto." (Hume cit in Dorfles, 1988, p.175). A necessidade de fruição do código por meio da acção permite que o acesso à verdade do sujeito seja entendida pelo utilizador. Esta reflexão reforça o entendimento do método em design ser um processo com uma linguagem capaz de atribuir um significado à realidade.

A hermenêutica, segundo Foucault, aproxima-se da semelhança. "Denominaremos hermenêutica o conjunto dos conhecimentos e das técnicas que permitem fazer falar os signos e descobrir o seu sentido" (Foucault, 1998, p.85). Admitir que a hermenêutica é uma metodologia que fundamenta o exercício da interpretação em design, significa que se escolhe a fenomenologia como método que o designer aplica a si mesmo, para saber como deve operar e para se relacionar com o contexto. Um caminho que traduz um sentido à realidade (sujeito e objecto) e que atribui explicação ao pensamento. Um processo em que os intérpretes também são interpretados pelas próprias técnicas de interpretação. No caso desta investigação, isto significa que o designer dialoga com a realidade e se transforma para passar a não ser o que era antes. Então, a fenomenologia é um processo metamorfósico 
que engloba, em simultâneo, a transformação do sujeito e do contexto e cujo foco é o relacionamento entre os dois, tanto no que pode significar como no que parece revelar.

No caso de uma análise comparativa entre a hermenêutica e a semiótica, Bernard Bürdek defende, a propósito das diferenças entre as metodologias projectuais clássicas e o método de acção intelectual do design, que os métodos semióticos se relacionam aos signos e que os métodos hermenêuticos se associam à interpretação. "Mover-se dentro da hermenêutica é praticá-lo dentro de um campo de conhecimento onde a semiótica não é mais suficiente. Esta disciplina pertencente à filosofia deve, portanto, ser tratada de maneira especial, considerando que dela se inferem relações explicativas de grande importância para o design". (Bürdek, 1994, p.141). Esta análise entre semiótica e hermenêutica como hipóteses de metodologias para fundamentar o fenómeno da interpretação como método em design pode conduzir à conclusão imprudente de excluir uma das hipóteses, porque a leitura do contexto poderá solicitar uma investigação em que as duas técnicas avancem lado a lado. A hermenêutica pela sua natureza permite a averiguação e a redefinição dos problemas projectuais, um processo aberto às questões. "A análise do círculo hermenêutico é o que nos permite alcançar a compreensão e a articulação com outros campos" (Soares \& Pombo, 2010, p.57)."2 (Soares \& Pombo, 2010, p.57). O que significa que se o método projectual tradicional se orienta para o produto, o ciclo hermenêutico orienta-se para o processo. Um método inclusivo em que projectar é re-projectar e que assume a semiótica como experiência e competência do design.

\section{CONCLUSÃO}

A fenomenologia apresenta-se como alternativa aos métodos tradicionais. Por um lado, o método intuitivo que permite um conhecimento imediato e que se traduz por uma convicção forte. Por outro lado, o método indutivo que depende da experimentação para alcançar um resultado e que se relaciona com a ciência.

Perante o problema inicial de tentar compreender o designer como intérprete por meio da hipótese da interpretação como método em design, concluí-se que a interpretação, para ser um método no design, deve fornecer o máximo de oportunidades, de circunstâncias. Para ser um método a considerar, a interpretação deve comportar-se como inovação, como mudança e não como uma garantia ou como uma repetição. Então, a fenomenologia surge como método e a hermenêutica como

\footnotetext{
${ }^{1}$ Tradução livre dos autores: "Moverse dentro de la hermenéutica es hacerlo dentro de un campo del conocimiento donde la semiótica ha dejado de ser suficiente. Esta disciplina perteneciente a la filosofía debe por tanto tratarse de un modo especial, considerando que de ella se infieren relaciones explicativas de gran importancia para el diseño" (Bürdek, 1994, p.141).

2 "The analysis of the hermeneutic circle is what allows us the understanding of the articulation with other fields" (Soares $\&$ Pombo, 2010, p.57).
} 
metodologia que, perante o problema da interpretação como método em design, controlará todo o processo. A interpretação é o sentido metodológico da descrição fenomenológica, ou seja, a maneira, a técnica que o designer actuará para descrever o relacionamento que tem com o mundo e, o resultado será a compreensão dessa ligação entre sujeito e contexto. 


\section{REFERÊNCIAS}

BARTHES, R. Mitologias. (1er Ed.1957). Lisboa: Edições 70, Lda. , 2007 BÜRDEK, B. E. Diseño. Historia, teoria y práctica del diseño industrial. (F. V. Lópes-Manzanares, Trans.). Barcelona: Ediciones Gustavo Gili. 1994

CROSS, N. Designerly Ways of Knowing. London: Springer. 2006 DORFLES, G. Elogio da Desarmonia. Colecção Arte e Comunicação. Lisboa: Edições 70. 1988

FOUCAULT, M. As Palavras e as Coisas. (1er Ed.1966). Lisboa: Edições 70. 1998. GADAMER, H.G. Verdad y Método II. Salamanca: Sígueme. 2002.

KRIPPENDORFF, K. The Semantic Turn: A New Foundation for Design. Philadelphia: University of Pennsylvania. 2005

RICOEUR, P. Teoria da Interpretação. Lisboa: Edições 70. 2005.

RICOEUR, P. Do Texto à Acção. Trad. Alcino Cartaxo e Maria José Sarabando. Porto: RÉS. 1989.

SOARES, L. POMBO, F. The Interpretation as a Method in Design or the Designer as an Interpreter. In: 1st International Congress of Design and Innovation of Catalonia. Escola Superior de Disseny, Universitat Ramon Llull, 2010. p.57 